\title{
Spectral Analysis Of Business Cycles \\ In The Visegrad Group Countries
}

\begin{abstract}
This paper examines the business cycle properties of Visegrad group countries. The main objective is to identify business cycles in these countries and to study the relationships between them. The author applies a modification of the Fourier analysis to estimate cycle amplitudes and frequencies. This allows for a more precise estimation of cycle characteristics than the traditional approach. The cross-spectral analysis of GDP cyclical components for the Czech Republic, Hungary, Poland and Slovakia makes it possible to assess the degree of business cycle synchronization between the countries.
\end{abstract}

Keywords: business cycle, synchronization, spectral analysis, Fourier representation

JEL: C22, C52, E32, F44

\section{Introduction}

Levels of economic activity and their changes over time have been the subject of researchers' interest since the beginning of the study of economics as an academic discipline. Scholars initially focused on the long-term equilibrium, and short term changes in the growth rate were treated as random disturbances in long-term growth.

\footnotetext{
* Ph.D., Maria Curie-Skłodowska University in Lublin, Faculty of Economics, Department of Statistics and Econometrics, e-mail: akijek@poczta.umcs.lublin.pl
} 
Studies into changes in economic situations are conducted in two ways. The first is research on long-term growth, while the second is the analysis of cyclical economic developments. Economic growth theories explain long-term movements in production. Simultaneous with long term growth surveys, studies on the movements of economic variables have been conducted (Hodrick, Prescott 1980, Kydland, Prescott 1990, Stock, Watson 2005). Business cycles differ in duration, amplitude, industrial and geographical scope, and in the degree of uniformity between countries. This latter feature of the cycles relates to the problem of business cycle synchronization.

Studies on business cycle synchronization between European countries are mainly related to the functioning of the European Monetary Union (EMU). Economic scientists examine the degree of business cycle synchronization between members of the EMU or between potential candidates and euro zone members (Forni at al. 2000, Artis et al. 2004a, Camacho et al.2008, AguiarConraria, Soares 2011). Research into other groups of countries do not arouse so much interest among economic scientists.

This study is focused on the one of the most significant cooperation groups in the Central and Eastern Europe, namely the Visegrad Group (also known as the Visegrad Four or simply V4). It reflects the efforts of these countries of the Central European region to work together in a number of fields of common interest within the all-European integration process. The V4 cooperation, mainly based on the historical links and geographical proximity, is regarded as the most clearly profiled initiative in the region.

The economies of the V4 countries are similar in many ways. They are post-communist economies, with a relatively large share of industry, strongly dependent on foreign capital and on import of energy resources from Russia. Their largest trading partner is Germany. Despite these similarities and common political initiatives, the actual economic cooperation between the Visegrad Four is low. Instead, they rather compete for foreign investment and markets. It is interesting to examine how similar this group of Eastern European countries are in terms of changes in their economic situation. This paper is intended to study the linkages between business cycles of the V4 countries (Czech Republic, Hungary, Poland and Slovakia) in order to assess the actual level of their synchronization. For this purpose the business cycles for these countries will be identified and the analysis of their synchronization will be carried out. 


\section{Literature review}

Business cycle estimation depends on the definition of economic activity fluctuations. This determines the choice of the mathematical and statistical methods used to identify business cycles.

Burns and Mitchell's proposed definition of a cycle (1946) is most often quoted by the scholars conducting business cycle studies. According to them, a business cycle consists of four distinct phases that evolve from one into another: expansion, recession, depression, and revival. A different view on business cycles was presented by Lucas (1977), who does not interpret cycles as inevitable transitions between different phases of the cycle. He treats a business cycle as a process of oscillation of GNP around a long-term trend.

Due to the periodic nature of the changes in the economic situation, its analysis requires the estimation of components mainly reflecting long-term economic growth and the business cycle.

For a long time, the dominant approach to modeling growth and fluctuations in economic activity was to treat them as the sum of polynomial deterministic trends, and stochastic deviations from the trends were considered to be a residual cyclical component. The deviations from the trend were assumed to be stationary, which in turn led to the construction of trend-stationary models. In the 1980s, a difference-stationary process became an alternative to trend-stationary models. Autoregressive integrated moving average (ARIMA) models were applied to macroeconomic variables. Authors used ARIMA models to describe the long-term trend in real GDP and its link with the business cycle (Beveridge, Nelson, 1981, Nelson, Plosser, 1982, Campbell, Mankiw, 1987). The use of a deterministic trend for long-term growth characteristics results in the assignment of too much variability to cyclical fluctuations, while the use of a stochastic trend leaves too little room for volatility in fluctuations (Zarnowitz, Ozyildrim 2001).

A compromise is to use the unobserved components model proposed by Harvey (1985) and Clark (1987). In their approach, the trend is smoothed and cycles have a high amplitude and are stable. Watson (1986) and Stock and Watson (1988) analyzed the difference between the Beveridge-Nelson approach and the unobserved components model. In the unobserved components model, restrictions are imposed on the structure of the stochastic trend and the cyclical component, and cross-correlations between both components' innovations. Harvey $(1989,2000)$ analyzed and comprehensively described the structure of these models.

Another concept of decomposition of the time series is to apply frequency filters. The essence of this method is the extraction of the separate components at different frequencies. Baxter and King (1995), Hodrick and Prescott (1997) 
and Christiano and Fitzgerald (1999) presented these methods and the results of their analysis of cycles in the United States using a frequency filter.

In this article I present different approaches to the analysis of business cycles and propose a modification of the Fourier analysis that can be applied to accurately measure cycle characteristics.

Various methods are applied in order to assess of the degree of cycle synchronization. One of the most popular tools is the Pearson correlation coefficient, which measures the degree of the co-movement in time domain. Its main drawback is lack of information about frequency horizons. Forni et al. (2000) and Lee (2012) used a dynamic factor model to explore the business cycle co-movements across countries in Europe. On the other hand, Artis et al. (2004a) applied Markov switching vector autoregression models to determine the dynamics of a European business cycle. Harding and Pagan (2006) demonstrated methods of measuring and testing the degree of synchronization. A different approach to the study of business cycles, in both time and frequency domains, is wavelet analysis (Crowley, Lee 2005, Aguiar-Conraria, Soares 2011).

The empirical part of this paper includes an analysis of production movements in Visegrad group countries. The V4 cooperation, mainly based on the historical links and geographical proximity, is regarded as the most clearly profiled initiative in Central Europe. Kaposzta and Nagy (2015) state that the cohesion among the Visegrad countries has been growing, but that countryspecific challenges still matter. They also suggest that economic cooperation needs to be strengthened.

Although many empirical studies focus on the business cycles synchronization between Central and Eastern European Countries and other EU countries (e.g. Backus et al. 1992, Artis et al. 2004b, Fidrmuc, Korhonen 2006, Darvas, Szapary 2008), there is a lack of research on the co-movements of economic cycles within the Visegrad region. One of the few works in this field is research conducted by Hanus and Vacha (2015). The authors apply the wavelet techniques to study the process of synchronization of the Visegrad Four. As such, it is worthwhile further examining, using different methods, whether cooperation between members of the V4 is reflected in the integration in the economic field (Inotai, Sass 1994). It is interesting whether the functioning of this group in its current form provides economic results for the member countries.

In order to assess the results of this cooperation, the following hypothesis is stated: The Visegrad countries have different business cycles, and only the Czech Republic and Slovakia have a high business cycle synchronization.

The first part of the hypothesis statement is formulated taking into account the nature of the partnership between the V4 countries. Despite the similarity in the level of their economic development, their cooperation is based 
mainly on efforts aimed at political cooperation. In the economic field the level of cooperation is low, and instead there is rather competition between countries for foreign investment and markets. For this reason, a low degree of business cycles' synchronization can be expected between the member countries. The second part of hypothesis is the result of the nearly 75 years of common history and economic relations between the Czech Republic and Slovakia.

I apply the univariate and multivariate methods of cycle measurement to identify business cycles and verify their synchronization between countries.

\section{Methodology}

Spectral analysis is a method used to estimate the spectral density function or spectrum of a given time series. Its goal is to determine the contributions of various periodic components with different frequencies in the time series. This method analyzes the properties of the series in the frequency domain, and it is complementary to the analysis in the time domain, which focuses on the covariance function. Any covariance-stationary process has both a time-domain representation and a frequency-domain representation, and any feature of the data that can be described by one representation can equally well be described by the other representation (Hamilton 1994).

\subsection{Fourier analysis and its modification}

The Fourier analysis is basically concerned with approximating a function of time by a sum of sine of cosine terms (Priestley 1981), called the Fourier series representation.

When $T$ is even, the Fourier representation of the time series, $y_{t}$, is:

$$
y_{t}=\hat{\mu}+\sum_{i=1}^{T / 2-1}\left\{\hat{\alpha}_{i} \sin \left(\omega_{i} t\right)+\hat{\delta}_{i} \cos \left(\omega_{i} t\right)\right\}+\hat{\delta}_{T / 2} \cos \left(\omega_{T / 2} t\right),
$$

where:

$\omega_{i}=2 \pi j / T, \hat{\mu}$ is the sample mean and $\hat{\alpha}_{i}, \hat{\delta}_{i}$ are coefficients.

If $T$ is odd, the time series can be expressed as:

$$
y_{t}=\hat{\mu}+\sum_{i=1}^{(T-1) / 2}\left\{\hat{\alpha}_{i} \sin \left[\omega_{i}(t-1)\right]+\hat{\delta}_{i} \cos \left[\omega_{i}(t-1)\right]\right\} .
$$


Since the components in the equation are mutually orthogonal, each one explains a specific part of the variance of the series. It is worth noting that the Fourier analysis partitions the variability of the series for $T$ even into components at frequencies $2 \pi / T, 4 \pi / T, \ldots, \pi$, . These frequencies are discrete and depend on the length of the time series. This means that the analysis is limited to pre-established frequencies and consequently to pre-established wavelengths, which is not always appropriate and has no substantive justification. If one wants to study the contribution of the cycles for given frequencies to variation in the series, the traditional Fourier representation is of little use. For example, it is impossible to examine the contribution of a cycle with a length of 7 years based on an 18-year time series.

A simple but ineffective solution is to adjust the length of the time series to the length of the analyzed cycles. This requires a lengthening or a shortening of the series. It should be noted however that lengthening the series is not always a possible solution, and that shortening results in a loss of some information.

A solution to these limitations may be the proposition I put forth in this paper. It involves estimating the model with significant harmonics at frequencies that provide an explanation for the highest level of variance of the variable:

where $\omega_{i}, \omega_{j} \in(0, \pi]$.

$$
y_{t}=\mu+\sum_{i=1}^{p} \alpha_{i} \sin \left(\omega_{i} t\right)+\sum_{j=1}^{q} \delta_{j} \sin \left(\omega_{j} t\right)+\varepsilon_{t},
$$

In this model, the number of parameters is less than the number of observations, because it includes only significant harmonics. This approach allows for the precise estimation of the frequencies and amplitudes of the cycles that have the greatest contribution to the variance of the time series.

In order to obtain the above model, the following procedure is applied:

1. Estimation of the Fourier series coefficients. In this way, the contribution of each harmonic to the total variance of the series is determined.

2. Estimation of the parameters of the model with a constant and a harmonic with the greatest contribution to the total variance. During the estimation of parameters, the frequency of the harmonic is determined at the interval $\left(\omega_{i}-\pi / T, \omega_{i}+\pi / T\right]$, so as to minimize the sum of squared residuals.

3. Estimation of parameters of the model with the constant, harmonic component determined in the previous step as well as the harmonic with the second greatest contribution to the total variance. During the estimation of parameters, the frequency of harmonics with the second greatest contribution is determined at the interval $\left(\omega_{i}-\pi / T, \omega_{i}+\pi / T\right]$, so as to 
minimize the sum of squared residuals. If there are insignificant parameters in the model, they are removed.

4. Further steps. New harmonics enter the model using a procedure analogous to the previous step. The procedure ends when the model cannot be improved by the introduction of a significant harmonic.

The advantage of the proposed approach is that the model is not limited to the harmonics of discrete frequencies resulting from the length of the time series. In the traditional approach, any variation in the time series data that is in reality due to cycles with frequencies other than these particular values is attributed to one of these discrete frequencies. In the proposed modification, the frequencies of cycles can be precisely calculated. On the other hand, this method for determining the frequency of harmonics means that they are not orthogonal and, in consequence, they do not explain any specific part of the variance of the series.

\subsection{Periodogram analysis}

The primary tool for spectral analysis is the power spectrum of the process, which is a function that attributes the portion of variance in the process to the frequencies. For a covariance-stationary process $Y_{t}$ with absolutely summable autocovariances, the power spectrum at frequency $\omega$ can be expressed as:

$$
s_{Y}(\omega)=\frac{1}{2 \pi} \sum_{j=-\infty}^{\infty} \gamma_{j} e^{-i \omega j} .
$$

The obvious estimator of the power spectrum is the sample periodogram which, for the given $\omega$, is calculated as:

$$
\hat{s}_{y}(\omega)=\frac{1}{2 \pi} \sum_{j=-T+1}^{T-1} \hat{\gamma}_{j} e^{-i \omega j}=\frac{1}{2 \pi}\left[\hat{\gamma}_{0}+2 \sum_{j=1}^{T-1} \hat{\gamma}_{j} \cos (\omega j)\right] .
$$

The periodogram considers the discrete frequencies in the interval $[0, \pi]$. Although it is an asymptotically unbiased estimator of a population spectrum, it is not a consistent one. Although the periodogram is itself an inconsistent estimator, there are procedures for smoothing this factor.

Smoothing of the periodogram is carried out for both time and frequency. In the former, the population spectrum might be estimated with the weighted average of discrete values of the periodogram in a neighborhood around $\omega_{j}$, where the weights depend on the distance to it. Then we obtain:

$$
\hat{s}_{Y}\left(\omega_{j}\right)=\sum_{m=-h}^{h} \kappa_{m} \hat{s}_{y}\left(\omega_{j+m}\right),
$$


where $\kappa_{m}$ are weights and $h$ is a bandwidth parameter indicating the number of frequencies useful for estimating the power spectrum. The weights sum to unity:

$$
\sum_{m=-h}^{h} \kappa_{m}=1
$$

A possible approach for determining weights is to assume them to be proportional to $h+1-|m|$ as in Hamilton (1994)

$$
\kappa_{m}=\frac{h+1-|m|}{(h+1)^{2}}, m=-h,-h+1, \ldots, h-1, h .
$$

The second type of estimation procedure consists of taking a Fourier transform of thee truncated weighted sample autocovariances function. Thus:

$$
\hat{s}_{Y}(\omega)=\frac{1}{2 \pi}\left[\hat{\gamma}_{0}+2 \sum_{j=1}^{q} \kappa_{j} \hat{\gamma}_{j} \cos (\omega j)\right],
$$

where $\kappa_{j}$ are weights called the lag window and $q$ is a truncation point. The two popular sets of weights are the Barlett (1950) and Parzen (1961) windows. The Barlett window is as follows:

$$
\kappa_{j}= \begin{cases}1-\frac{|j|}{q+1} & \text { dla }|j| \leq q \\ 0 & \text { dla }|j|>q\end{cases}
$$

and the Parzen window is calculated as:

$$
\kappa_{j}=\left\{\begin{array}{lr}
1-6(j / q)^{2}+6(|j| / q)^{3} & \text { dla }|j| \leq q / 2 \\
2(1-j / q)^{3} & \text { dla } q / 2 \leq|j| \leq q . \\
0 & \text { dla }|j|>q
\end{array}\right.
$$

The choice of bandwidth parameter $h$ and truncation point $q$ is difficult and little advice is available in the literature. It is crucial to find the optimum balance between bias and variance. The choice can be made arbitrarily, so as to obtain the most reliable assessment, or using statistical criteria. A useful rough guide is to choose $q$ to be equal to $\operatorname{int}(2 \sqrt{ } T)$, which ensures the asymptotic situation that as $N \rightarrow \infty$, so also does $M \rightarrow \infty$, but in such a way that $M / N \rightarrow \infty$ (Chatfield 1996). 


\subsection{Cross-spectral analysis}

The extension of a one-dimensional spectral analysis to a twodimensional situation is represented by cross-spectral analysis. By analogy with the equation for the power spectrum, the cross-spectrum of a discrete bivariate process is defined as the Fourier transform of the cross-covariance function:

$$
s_{Y X}(\omega)=\frac{1}{2 \pi} \sum_{k=-\infty}^{\infty} \gamma_{Y X}^{(k)} e^{-i \omega k}=\frac{1}{2 \pi} \sum_{k=-\infty}^{\infty} \gamma_{Y X}^{(k)}[\cos (\omega k)-i \sin (\omega k)] .
$$

where $\gamma_{Y X}^{(k)}=\operatorname{cov}\left(X_{t}, Y_{t-k}\right)$ is the cross-covariance of two discrete time series $X$ and $Y$ lagged by $k$ periods. The cross spectrum can be written in terms of its real and imaginary components as:

$$
s_{Y X}(\omega)=c_{Y X}(\omega)+i \cdot q_{Y X}(\omega) .
$$

The real part of the cross spectrum, called the co-spectrum, is given by

$$
c_{Y X}(\omega)=\frac{1}{2 \pi} \sum_{k=-\infty}^{\infty} \gamma_{Y X}^{(k)} \cos (\omega k)
$$

and the imaginary part, called the quadrature spectrum, takes the form:

$$
q_{Y X}(\omega)=\frac{1}{2 \pi} \sum_{k=-\infty}^{\infty} \gamma_{Y X}^{(k)} \sin (\omega k) .
$$

The co-spectrum and quadrature spectra are used to determine the crossspectral statistics: coherence, gain and phase shift. All these measures are functions of frequency and thus make it possible to study the relationship between the variables at different frequencies. Coherence, gain and phase shift are calculated as follows (Sargent 1987, Hamilton 1994):

$$
\begin{gathered}
h_{Y X}(\omega)=\frac{\left[c_{Y X}(\omega)\right]^{2}+\left[q_{Y X}(\omega)\right]^{2}}{s_{Y}(\omega) s_{X}(\omega)}, \\
g_{Y X}(\omega)=\frac{\left[\left[c_{Y X}(\omega)\right]^{2}+\left[q_{Y X}(\omega)\right]^{2}\right]^{\frac{1}{2}}}{s_{X}(\omega)}, \ldots . . \\
\varphi_{Y X}(\omega)=\tan ^{-1}\left[-\frac{q_{Y X}(\omega)}{c_{Y X}(\omega)}\right] .
\end{gathered}
$$


The coherence is the square of the linear correlation coefficient between the two series at frequency $\omega$. It is interpreted as the coefficient of determination for the linear regression of one variable relative to the other. Thus, coherence measures how much of the variance in one variable is explained by the variance of the other variable at frequency $\omega$. The gain is an absolute value of the regression coefficient of process $Y$ on process $X$ at frequency $\omega$. It provides information about relationships between amplitudes of the two processes at a given frequency. The phase shift indicates the shift between two series at frequency $\omega$.

An important property of gain and phase shift is that they are more informative for high values of coherence (Warner 1998). This is due to the fact that the error of estimation for these measures is inversely proportional to the square of coherence. This means that a decline in the value of coherence increases the estimation error for gain and phase shift. Thus, a sufficiently high level of coherence for a given frequency is needed to accurately estimate the relationships between amplitudes and time shifts between processes.

The estimator of cross-spectrum is the sample cross periodogram from $X$ to $Y$ at frequency $\omega$ and this is calculated as:

$$
\hat{s}_{y x}(\omega)=\frac{1}{2 \pi} \sum_{k=-T+1}^{T-1} \hat{\gamma}_{Y X}^{(k)} e^{-i \omega k}=\frac{1}{2 \pi} \sum_{k=-T+1}^{T-1} \hat{\gamma}_{Y X}^{(k)}[\cos (\omega k)-i \sin (\omega k)] .
$$

Thus, a sample co-spectrum and quadrature spectrum are estimated as follows:

$$
\begin{aligned}
& \hat{c}_{y x}(\omega)=\frac{1}{2 \pi} \sum_{k=-T+1}^{T-1} \hat{\gamma}_{Y X}^{(k)} \cos (\omega k), \\
& \hat{q}_{y x}(\omega)=\frac{1}{2 \pi} \sum_{k=-T+1}^{T-1} \hat{\gamma}_{Y X}^{(k)} \sin (\omega k),
\end{aligned}
$$

The smoothing method of power spectrum, co-spectrum and quadrature spectrum is analogous to that used in a one-dimensional case.

\section{Study results}

The analysis of the cyclical behavior of Gross Domestic Product (GDP) was conducted for the Visegrad group countries: Czech Republic (CZE), Hungry (HUN), Poland (POL) and Slovakia (SVK). The methods presented in the previous section were used for a periodicity analysis of a time series of GDP. 
The study deals with time series quarterly data of GDP for the Czech Republic, Hungary, Poland and Slovakia for the period 1997Q1-2015Q4. Initially, input GDP values are transformed into a common logarithm and deseasonalized using the Tramo-Seats procedure. Then, the Hodrick-Prescott filter is applied to extract cyclical components from the series.

The models with harmonics for cyclical components were built using modification of the Fourier analysis. The introduction of harmonic components into the models was performed stepwise, at a significance level of 0.05 . Then, the obtained models were used to determine forecasts for GDP in 2016-2018 with 95\% confidence intervals. The parameter estimates of the models for GDP are reported in Table 1. The cyclical components of GDP, theoretical values and forecasts, together with the corresponding cyclical harmonics, are shown in Figure 1. The left panel of the chart shows the cyclical components of GDP, theoretical values obtained from models and forecasts for cyclical components. The right panel of the chart visualizes the distribution of the five harmonics with the highest amplitudes.

Table 1. Parameter estimates of models with cyclical components for GDP for Czech Republic, Hungary, Poland and Slovakia

\begin{tabular}{|c|c|c|c|c|c|}
\hline \multicolumn{3}{|c|}{ Czech Republic } & \multicolumn{3}{c|}{ Hungary } \\
\hline $\begin{array}{c}\text { cyclical } \\
\text { component }\end{array}$ & $\begin{array}{c}\text { cycle length } \\
\text { (in years) }\end{array}$ & $\begin{array}{c}\text { parameter } \\
\text { estimate }\end{array}$ & $\begin{array}{c}\text { cyclical } \\
\text { component }\end{array}$ & $\begin{array}{c}\text { cycle length } \\
\text { in years) }\end{array}$ & $\begin{array}{c}\text { parameter } \\
\text { estimate }\end{array}$ \\
\hline $\cos (0.048 \pi)$ & 10.4 & $0.009^{* * *}$ & $\cos (0.032 \pi)$ & 15.7 & $-0.003^{* * *}$ \\
\hline $\sin (0.058 \pi)$ & 8.7 & $0.007^{* * *}$ & $\cos (0.051 \pi)$ & 9.9 & $0.014^{* * *}$ \\
\hline $\sin (0.079 \pi)$ & 6.4 & $-0.006^{* * *}$ & $\sin (0.082 \pi)$ & 6.1 & $-0.006^{* * *}$ \\
\hline $\cos (0.1 \pi)$ & 5 & $0.013^{* * *}$ & $\cos (0.118 \pi)$ & 4.2 & $-0.005^{* * *}$ \\
\hline $\cos (0.135 \pi)$ & 3.7 & $0.010^{* * *}$ & $\sin (0.145 \pi)$ & 3.5 & $0.005^{* * *}$ \\
\hline $\cos (0.154 \pi)$ & 3.3 & $-0.003^{* * *}$ & $\cos (0.171 \pi)$ & 2.9 & $0.004^{* * *}$ \\
\hline $\sin (0.185 \pi)$ & 2.7 & $0.003^{* * *}$ & $\sin (0.197 \pi)$ & 2.5 & $-0.003^{* * *}$ \\
\hline \multicolumn{7}{|c|}{ Poland } & & & Slovakia & \\
\hline $\begin{array}{c}\text { cyclical } \\
\operatorname{component}\end{array}$ & $\begin{array}{c}\text { cycle length } \\
\text { (in years) }\end{array}$ & $\begin{array}{c}\text { parameter } \\
\text { estimate }\end{array}$ & $\begin{array}{c}\operatorname{cyclical} \\
\operatorname{component}\end{array}$ & $\begin{array}{c}\text { cycle length } \\
\text { in years) }\end{array}$ & $\begin{array}{c}\text { parameter } \\
\text { estimate }\end{array}$ \\
\hline $\sin (0.052 \pi)$ & 9.5 & $0.007^{* * *}$ & $\sin (0.055 \pi)$ & 9 & $0.032^{* * *}$ \\
\hline $\cos (0.059 \pi)$ & 8.4 & $-0.003^{* *}$ & $\cos (0.063 \pi)$ & 7.9 & $0.032^{* * *}$ \\
\hline $\cos (0.077 \pi)$ & 6.5 & $-0.007^{* * *}$ & $\sin (0.071 \pi)$ & 7 & $-0.034^{* * *}$ \\
\hline $\sin (0.125 \pi)$ & 4 & $-0.007^{* * *}$ & $\cos (0.079 \pi)$ & 6.3 & $-0.010^{* * *}$ \\
\hline $\cos (0.136 \pi)$ & 3.7 & $0.004^{* * *}$ & $\sin (0.1 \pi)$ & 5 & $0.003^{*}$ \\
\hline $\cos (0.158 \pi)$ & 3.2 & $-0.003^{* * *}$ & $\cos (0.112 \pi)$ & 4.4 & $-0.009^{* * *}$ \\
\hline $\sin (0.258 \pi)$ & 1.9 & $-0.002^{* * *}$ & $\cos (0.145 \pi)$ & 3.5 & $-0.003^{* *}$ \\
\hline$-\sin )$
\end{tabular}

${ }^{*}$ - statistical significance at 0.1 level, ${ }^{* *}$ - statistical significance at 0.01 level, ${ }^{* * *}$ - statistical significance at 0.001 level.

Source: Own calculations. 
Figure 1. Cyclical components of GDP, theoretical values, forecasts and cyclical harmonics
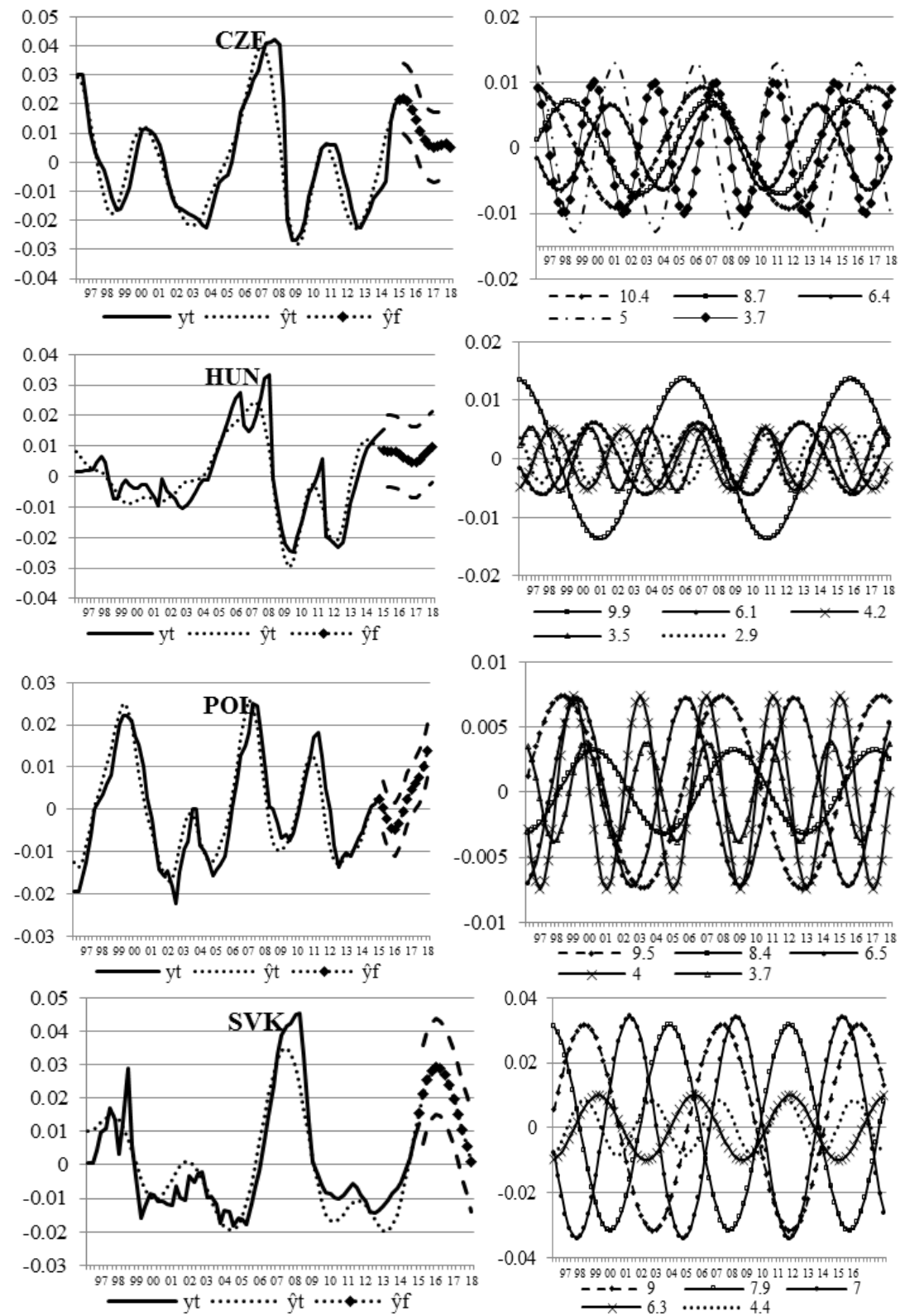

Left panel: yt - empirical values, $\hat{y} t$ - theoretical values obtained from models with harmonics, $y f-$ forecast ( $95 \%$ confidence interval). Right panel: numbers in the legend are lengths of harmonics (in years).

Source: Own calculations. 
In the case of the four countries, cycles of 9-10 years in length have the largest amplitudes. In the Czech Republic, cycles have similar amplitudes, as opposed to Hungary, where 10-year cycles are dominant. In Slovakia longer cycles have greater amplitudes than shorter ones, and in Poland the greatest amplitudes belong to 9.5, 6.5 and 4-year cycles. Imposition of periods of growth in long-term cycles determines the current period of a favorable economic and financial situation for the countries.

Forecasts for the cyclical component of GDP for the Czech Republic and Slovakia indicate a change in the trend of their economic and financial situations. This downturn is due to the transition to a decline phase of dominant harmonics. In contrast to these two countries, in Poland the growth trend for GDP will continue in the future and in Hungary the economic situation will stabilize.

In order to verify the agreed levels of volatility, periodograms for the cyclical component of GDP were also plotted. Periodograms were smoothed in the frequency domain using a Barlett and Parzen window, as proposed by Chatfield. These are presented in Figure 2.

Figure 2. Periodograms for cyclical components of GDP
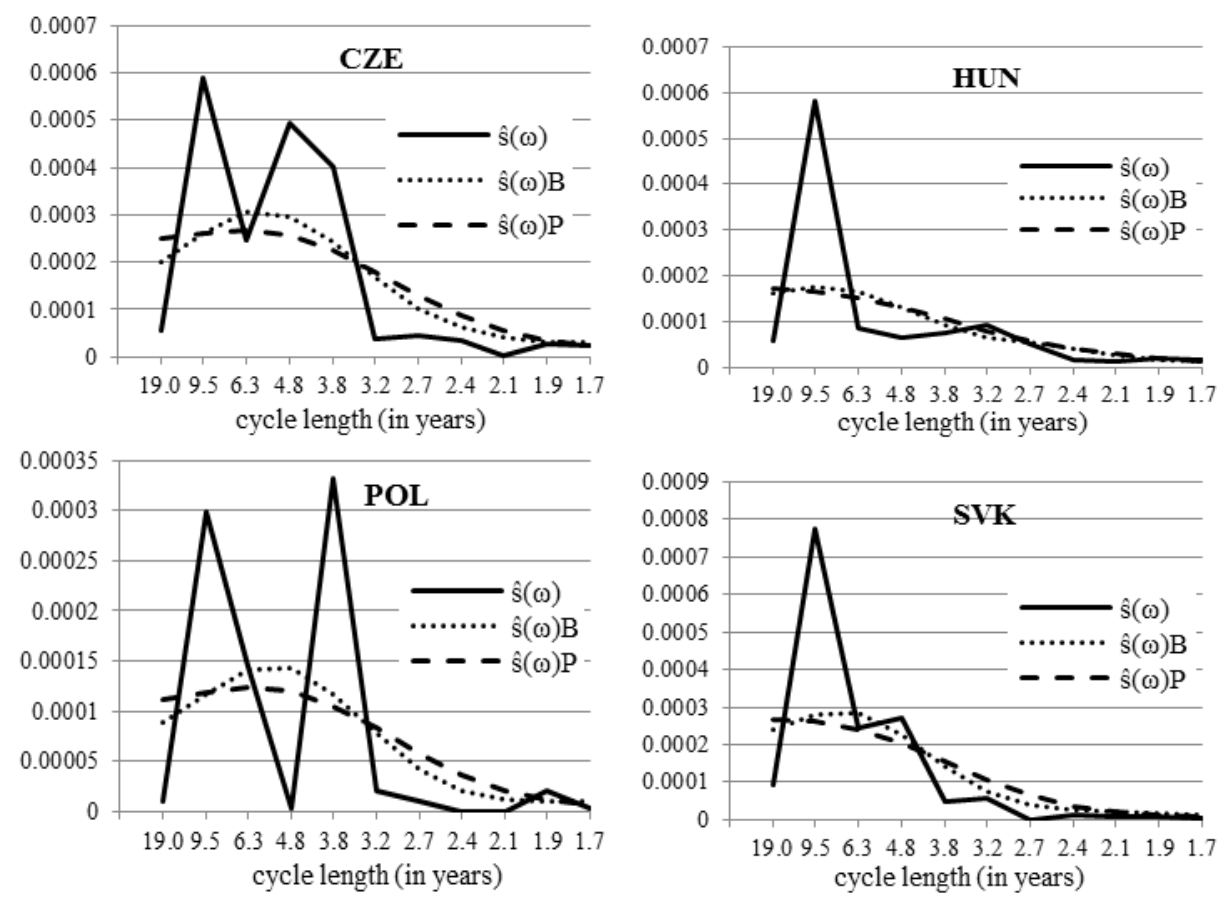

Source: Own calculations. 
Periodograms and smoothed periodograms confirm that cycles of approximately 9.5 years in length play a crucial role in explaining the variation of GDP. The significance of these cycles was confirmed both by the harmonic analysis, as well as by the evidence of the peaks found in the periodograms. Application of the models with harmonics as I have proposed enabled a precise estimate of the frequencies and lengths of cycles.

Next the cross-spectral statistics (coherence, gain and phase shift) were estimated for all pairs among the surveyed countries. For statistical estimations, the Parzen window was applied with a truncation point of 17 . The estimates of cross-spectral statistics for the Czech Republic, Hungary, Poland and Slovakia are shown in Figure 3. The dotted line on the graphs of coherence indicates a critical value at a 0.05 significance level. The graphs of gain and phase shift include confidence intervals at a 0.95 level.

Coherence for Slovakia and the Czech Republic has a value close to 1. In the case of Poland, however, coherence with the other three countries achieves statistically insignificant values for the adopted level of significance. Coherence for Hungary-Czech Republic and Slovakia-Hungary reaches values of about $0.5-0.7$, i.e. greater than the critical value. This demonstrates the strong relationship between the cyclical fluctuations of GDP between the Czech Republic, Hungary and Slovakia. Only the Polish cycles are independent from the other three countries' cycles. This means that gain and phase shift for Poland and the other countries are not informative due to high estimation errors.

Values for gain indicate that the cycles for Slovakia have the greatest amplitudes, and for Czech Republic the lowest. The phase shift between the Czech and Hungarian cycles shows that those for the former are ahead of those for the latter by about 1-2 quarters. In turn, the Czech and Hungarian cycles precede Slovak cycles by about 3-5 quarters. 
Figure 3. Coherence, gain and phase shift for cyclical components of GDP
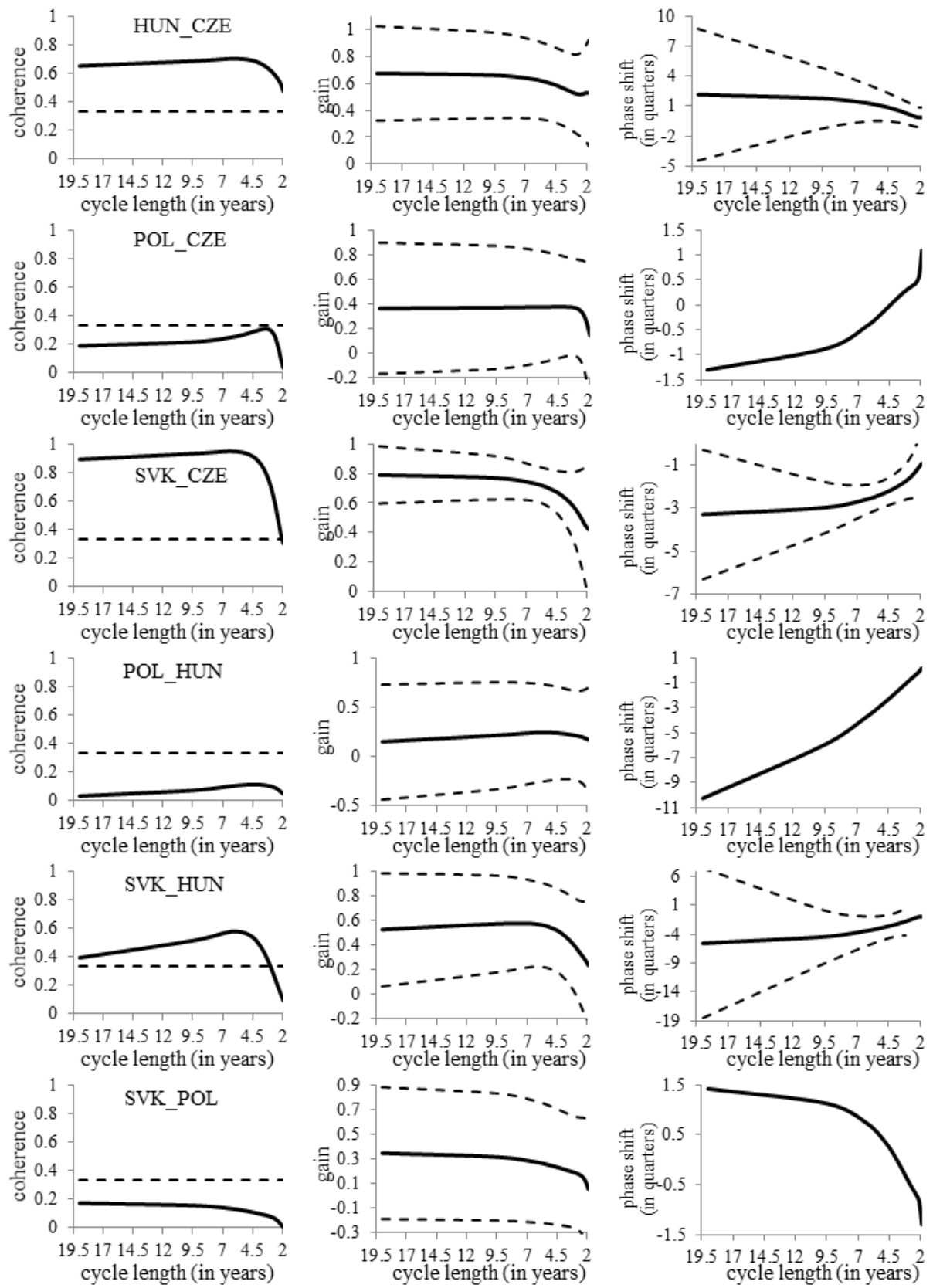

Source: Own calculations. 


\section{Conclusions}

This paper has focused on the problems of business cycle measurement. Particular attention has been paid to the problem of measurement precision in the context of business cycle characteristics. I have proposed a method for estimation of amplitudes and frequencies of the cycles, which is a modification of the Fourier analysis. The study has confirmed the dominant role of the 9-10 year cycles in explaining the variation in GDP in the Czech Republic, Hungry, Poland and Slovakia. Imposition of growth periods in long-term cycles contributes to the current period of economic growth in these countries. Cyclical component forecasts point to continued growth in Poland, stabilization in Hungary, and declines in the Czech Republic and Slovakia.

The business cycle synchronization is high only between the Czech Republic and Slovakia. This is not surprising in view of their nearly 75 years of common economic relations. Despite their disunion in 1992 and adoption of their own development paths, both economies are highly synchronized. In contrast, only the Polish cycles are independent of the other three countries' cycles. Hungarian cycles are significantly linked to the Czech and Slovak cycles, and more strongly to the former. The conclusion for Poland is consistent with the assumptions in the hypothesis, while for Hungry it is not.

This study makes it possible to assess cyclical movements of GDP in the Visegrad group countries. It has identified the significant cycles, indicated future developments, and evaluated the degree of business cycle synchronization between these countries.

\section{References}

Aguiar-Conraria L., Soares M.J. (2011), Business Cycle Synchronization and the Euro: a Wavelet Analysis, 'Journal of Macroeconomics', Vol. 33, 477-489.

Artis M., Krolzig H.M., Toro J. (2004a), The European Business Cycle, 'Oxford Economic Papers', 56, 1-44.

Artis M.J., Marcellino M., Proietti T. (2004b), Characterizing the business cycle for accession countries, CEPR Discussion Papers 4457.

Backus D.K., Kehoe P.J., Kydland F.E. (1992), International Real Business Cycles, 'Journal of Political Economy', Vol. 100, No. 4, 745-775.

Bartlett M.S. (1950), Periodogram Analysis and Continuous Spectra, 'Biometrika', Vol. 37, No. 1-2, 1-16. 
Baxter M., King R.G. (1995), Measuring Business Cycles: Approximate Band-Pass Filters for Economic Time Series, Working Paper No. 5022, National Bureau of Economic Research, Cambridge.

Beveridge S., Nelson C.R. (1981), A New Approach to Decomposition of Economic Time Series into Permanent and Transitory Components with Particular Attention to Measurement of the 'Business Cycle', 'Journal of Monetary Economics', 7, 151-174.

Burns A.F., Mitchell W.C. (1946), Measuring Business Cycles, N.Y.: National Bureau of Economic Research, New York.

Camacho M., Perez-Quiros G., Saiz L. (2008), Do European business cycles look like one?, 'Journal of Economic Dynamics and Control', Vol. 32, No. 7, 2165-2190.

Campbell J.Y., Mankiw N.G. (1987), Permanent and Transitory Components in Macroeconomic Fluctuations, 'American Economic Review' (Papers and Proceedings), 77, 111-117.

Chatfield C. (1996), The Analysis of Time Series: An Introduction, Chapman \& Hall, London.

Christiano L.J., Fitzgerald T.J. (1999), The Band Pass Filter, Working Paper No. 9906, Federal Reserve Bank of Cleveland.

Clark P.K. (1987), The Cyclical Component of U.S. Economic Activity, 'The Quaterly Journal of Economics', Vol. 102, 797-814.

Crowley P., Lee J. (2005), Decomposing the Co-movement of the Business Cycle: A Time-Frequency Analysis of Growth Cycles in the Euro Area, Bank of Finland discussion papers 12/2005.

Darvas Z., Szapary G. (2008), Business Cycle Synchronization in the Enlarged EU, 'Open Economies Review', Vol. 19, No. 1, 1-19.

Fidrmuc J., Korhonen I. (2006), Meta-analysis of the Business Cycle Correlation Between the Euro Area and the CEECs, 'Journal of Comparative Economics', Vol. 34, No. 3, 518-537.

Forni M., Hallin M., Lippi M., Reichlin L. (2000), The Generalized Dynamic-factor Model: Identification and Estimation, 'The Review of Economics and Statistics', Vol. 82, No. 4, 540-554.

Hamilton J.D. (1994), Time Series Analysis, Princeton University Press.

Hanus L., Vacha L. (2015), Business Cycle Synchronization of the Visegrad Four and the European Union, IES Working Paper: 19/2015.

Harding D., Pagan A. (2006), Synchronization of Cycles, 'Journal of Econometrics', Vol. 132, No. 1, 59-79.

Harvey A.C. (1985), Trends and Cycles in Macroeconomic Time Series, 'Journal of Business and Economic Statistics', Vol. 3, 216-227.

Harvey A.C. (1989), Forecasting, Structural Time Series Models and the Kalman Filter, Cambridge University Press, Cambridge, New York and Melbourne.

Harvey A.C. (2000), Trends Analysis, University of Cambridge, Faculty of Economics and Politics.

Hodrick R., Prescott E. (1980), Post-War U.S. Business Cycles: An Empirical Investigation, Working paper, Carnegie Mellon University. 
Hodrick R.J., Prescott E.C. (1997), Postwar U.S. Business Cycles: An Empirical Investigation, 'Journal of Money Credit and Banking', Vol. 29, No. 1, 1-16.

Inotai A., Sass M. (1994), Economic Integration of Visegrad Countries. Facts and Scenarios, 'Eastern European Economics', Vol. 32, No. 6, 6-23.

Kaposzta J., Nagy H. (2015), Status Report about the Progress of the Visegrad Countries in Relation to Europe 2020 Targets, 'European Spatial Research and Policy', Vol. 22, No. 1, 81-99.

Kydland F., Prescott C. (1990), Business Cycles: Real Facts and A Monetary Myth, Federal Reserve Bank of Minneapolis, Quarterly Review (Spring), 3-18.

Lee J. (2012), Measuring Business Cycle Comovements in Europe: Evidence from a Dynamic Factor Model with Time-varying Parameters, 'Economics Letters', Vol. 115, No. 3, 438-440.

Lucas R.E. (1977), Understanding Business Cycles, [in:] Brunner K., Meltzer A. H. (eds.), Stabilization of the Domestic and International Economy, Carnegie-Rochester Conference Series on Public Policy 5, Amsterdam: North Holland, 7-29.

Nelson C.R., Plosser C.I. (1982), Trends and Random Walks in Macroeconomic Time Series: Some Evidence and Implications, 'Journal of Monetary Economics', 10, 139-162.

Parzen E. (1961), Mathematical considerations in the estimation of spectra: Comments on the discussion of Messers, Tukey, and Goodman, 'echnometrics', 3, 167-190; 232-234.

Priestley M.B. (1981), Spectral Analysis and Time Series, Vols 1 and 2, Academic Press, London.

Stock J., Watson M. (2005), Understanding Changes in International Business Cycle, 'Journal of European Economic Association', Vol. 3, No. 5, 968-1006.

Stock J.H., Watson M.W. (1988), Variable Trends in Economic Time Series, 'Journal of Economic Perspectives', Vol. 2, 147-174.

Warner R.M. (1998), Spectral Analysis of Time Series Data, 'The Guilford Press', New York.

Watson M.W. (1986), Univariate Detrending Methods with Stochastics Trends, 'Journal of Monetary Economics', Vol. 18, No. 1, 49-75.

Zarnowitz V., Ozyildirim A. (2001), Time Series Decomposition and Measurement of Business Cycles, Trends and Growth Cycles, 'Economics Program Working Paper Series', The Conference Board, New York. 


\section{Streszczenie}

\section{ANALIZA SPEKTRALNA CYKLI KONIUNKTURALNYCH KRAJÓW GRUPY WYSZEHRADZKIEJ}

$W$ artykule zbadano wlaściwości cykli koniunkturalnych $w$ krajach Grupy Wyszehradzkiej. Gtównym celem jest identyfikacja cykli koniunkturalnych $w$ tych państwach $i$ analiza powiqzań pomiędzy nimi. Autor wykorzystuje modyfikacje transformaty Fouriera do estymacji amplitud i częstotliwości cykli. Pozwala ona na precyzyjniejsze oszacowanie charakterystyk cykli niż w tradycyjnym podejściu. Analiza cross-spektralna komponentów cyklicznych PKB dla Czech, Wegier, Polski i Stowacji umożliwita ocenę stopnia synchronizacji cykli koniunkturalnych w tych krajach.

Slowa kluczowe: cykle koniunkturalne, synchronizacja, analiza spektralna, transformata Fouriera 